\title{
AUSTIN, DEHYDROAUSTIN AND OTHER METABOLITES FROM Penicillium brasilianum
}

\author{
Betânia T. M. Schürmann \\ Escola de Farmácia, Universidade Federal de Ouro Preto, Rua Costa Sena, 171, 35400-000 Ouro Preto - MG, Brasil \\ William S. T. Sallum e Jacqueline A. Takahashi* \\ Departamento de Química, Universidade Federal de Minas Gerais, Av. Antonio Carlos, 6627, 31270-901 Belo Horizonte - MG, Brasil
}

Recebido em 23/6/09; aceito em 19/1/10; publicado na web em 3/5/10

\begin{abstract}
A culture of P. brasilianum, isolated from soil collected at the Serra do Cipó National Park, in Minas Gerais State (Brazil), was grown for 25 days on a dextrose-peptone-salts medium. The corresponding ethylacetate extract was column chromatographed and four compounds were isolated: austin, dehydroaustin, D-mannitol and penicillic acid. This is, in the best of our knowledge, the first time that the meroterpenes austin and dehydroaustin have been isolated from this species. Activity of the extract and isolated compounds was tested against six bacteria and for acetylcholinesterase inhibition. Penicillic acid showed high activity in both tests.
\end{abstract}

Keywords: Austin; dehydroaustin; Penicillium brasilianum.

\section{INTRODUCTION}

Penicillium brasilianum Batista is a fungal species commonly found in soil. Several bioactive secondary metabolites were reported from this species, such as viridicatum toxin, verrucologen, fumitremorgin A, B and penicillic acid. ${ }^{1}$ The latter compound presents antibacterial, antiviral, cytotoxic, carcinogenic and antifungal activities ${ }^{2,3}$ while verrucologen and fumitremorgins have in vitro citotoxic activity against Ehrlich carcinoma tumor cells. ${ }^{4}$ Isolation of novel compounds with convulsive activity from this species has been recently reported and named brasiliamides $\mathrm{A}, \mathrm{B},{ }^{5} \mathrm{C}$, $\mathrm{D}$ and $\mathrm{E} .{ }^{6}$ Brasiliamides A, B, meroterpenoids preaustinoid A1, preaustinoid B2, austinolide along with, brasiliamide F, were also reported as metabolites from Penicillium brasilianum, isolated as an endophyte from Melia azedarach. ${ }^{7}$ Brasiliamide A presented bacteriostatic activity against $B$. subtilis. ${ }^{7}$

Penicillium brasilianum Batista was one of the 150 fungal species isolated from soil of the Serra do Cipó National Park (MG, Brazil) and its ethylacetate extract was identified as one of the most active against Gram-positive and Gram-negative bacteria on a screening for antibacterial compounds, thus motivating the study of the metabolites responsible for the antibacterial activity in this extract. ${ }^{8}$

Meroterpenes are secondary metabolites found in plants, marine invertebrates and microorganisms that have been frequently isolated in fungi from Penicillium and Aspergillus genera. ${ }^{9}$ Austin is a good representative of this class, having been isolated for the first time in 1976 by Chexal et al. from a culture of Aspergillus ustus. ${ }^{10}$ Later, in 1994, it was isolated, along with five other meroterpenes, from Penicillium sp. ${ }^{11}$ Several Austin-like compounds have been reported from an endophyte species of Penicillium cultivated in rice: preaustinoid $\mathrm{A}$ and $\mathrm{B},{ }^{12}$ 7- $\beta$-acetoxydehydroaustin, neoaustin, dehydroaustin, austinoneol, ${ }^{13}$ preaustinoid A1, A2 and B1. ${ }^{14}$ Some of these derivatives showed activity against Escherichia coli, Bacillus sp and Pseudomonas aureginosa. ${ }^{12}$

Therefore, the aim of the present work was to investigate the chemical composition of the ethylacetate extract of $P$. brasilianum in order to determine the structure of the compound responsible for its high antibacterial activity. Since $P$. brasilianum metabolites have never been tested as acetylcholinesterase inhibitors, this bioassay was also carried out for the isolated compounds.

\section{EXPERIMENTAL}

Source and maintenance of Penicillium brasilianum and bacterial strains P. brasilianum (LAB 34) was isolated from soil collected at the Serra do Cipó National Park, in Minas Gerais State (Brazil) ${ }^{8}$ and belongs to the Biotechnology and Bioassays Laboratory at the Chemistry Department from the Universidade Federal de Minas Gerais, Brazil. This isolate was identified by L. M. de Abreu and then maintained on malt agar at $-86^{\circ} \mathrm{C}$ on an ultra-freezer. Bacterial strains used for antibacterial assays were: Staphylococcus aureus ATCC 29213, Listeria monocytogenes ATCC 15313 and Bacillus cereus ATCC 1177 (Gram positive) and Salmonela typhimurium ATCC 14028, Escherichia coli ATCC 25922 and Citrobacter freundii ATCC 8090 (Gram negative).

\section{Reagents and equipment}

Culture medium components were purchased from Biobrás (Montes Claros, Brazil). Solvents and eluants were purchased from Grupo Química (São Paulo, Brazil). Blanc and positive control discs were obtained from CECON (São Paulo, Brazil). Column grade silicagel (article 7734) and thin layer chromatography silicagel (article 7731) were purchased from Merck (Darmstadt, Germany). The Vortex apparatus used was an AP 56-Phoenix (Araraquara, Brazil). Melting points were determined on a Mettler FP80HT apparatus and are uncorrected. Infrared spectra were obtained on a Spectrum One FTIR Spectrometer (Perkin-Elmer). ${ }^{1} \mathrm{H}$ and ${ }^{13} \mathrm{C}$ Nuclear Magnetic Resonance spectra were obtained from Bruker DRX-400 and DRX 200 Advance Spectrometers.

\section{Metabolites production}

For metabolites production, a five-day-old inoculum containing $P$. brasilianum was prepared on an aqueous medium with the following composition (g/L): Dextrose (20.0), Peptone (5.0), $\mathrm{KH}_{2} \mathrm{PO}_{4}(1.0), \mathrm{MgSO}_{4} \cdot 7 \mathrm{H}_{2} \mathrm{O}(0.5)$ and $\mathrm{NaCl}$ (5.0). This inoculum was distributed among five conical flasks, each one containing one liter of the same medium. The growth took place at $25^{\circ} \mathrm{C}$, on static condition for 25 days, after which ethyl acetate was added to stop the growth. 


\section{Cultivation and extract preparation}

The mycelium was separated from the culture broth by vacuum filtration. Both mycelium and broth were extracted separately three times with ethyl acetate ( $300.0 \mathrm{~mL}$ for each extraction). The resulting layers were combined and the solvent was eliminated by evaporation by using a rotator vacuum distilling apparatus. TLC comparison of mycelium and broth extracts showed the same profile and they were combined leading to $12.0 \mathrm{~g}$ of crude extract.

\section{Metabolites purification}

The extract was fractionated by chromatography in a silica gel column $(10.0$ x $40.0 \mathrm{~cm})$ using, as eluents, hexane, ethyl acetate and methanol $100 \%$ and in mixtures of growing polarities leading to 190 fractions ( $250.0 \mathrm{~mL}$ each), which were combined in 46 groups, according to thin layer chromatography profiles. Group 36 comprised fractions eluted by a mixture of EtOAc/MeOH 1:1 and presented a solid that was filtered off and recrystallized from methanol furnishing white crystals $(\mathbf{1}, 56.0 \mathrm{mg})$ that was tentatively identified by ${ }^{1} \mathrm{H}$ and ${ }^{13} \mathrm{C}$ NMR and DEPT as D-mannitol (1). D-mannitol. m.p. $162-164{ }^{\circ} \mathrm{C}$ (rec. methanol), $[\alpha]_{\mathrm{D}}{ }^{20}+4.5\left(c 0.475, \mathrm{H}_{2} \mathrm{O}\right)$. IR (KBr): $3300(\mathrm{OH}){ }^{15}$

Group $18(687.9 \mathrm{mg})$, constituted by fractions eluted from hexane/ EtOAc 1:1, was again column chromatographed on silica gel using a gradient of hexane, dichloromethane and methanol; the group of fractions eluted with $\mathrm{CH}_{2} \mathrm{Cl}_{2} / \mathrm{MeOH}$ 98:02 (345.0 mg) from this column was filtered on a neutral alumina column using hexane/EtOAc 1:1 as the eluent to remove a polar undesirable compound and the resulting material was again submitted to silica gel column chromatography resulting on a white solid $(34.0 \mathrm{mg})$, that was identified by infrared, uni- and bidimensional NMR as austin ${ }^{12}$. Austin (2) m.p. 296-300 ${ }^{\circ} \mathrm{C}$. IR $(\mathrm{KBr}) 3487(\mathrm{OH}), 2991$ and $2946(\mathrm{CH}), 1773(\mathrm{C}=\mathrm{O}), 1745$ ( $\gamma$-lactone $\mathrm{C}=\mathrm{O}), 1704$ ( $\delta$-lactone $\mathrm{C}=\mathrm{O}), 1226$ and $1209 \mathrm{~cm}^{-1}[-\mathrm{C}(=\mathrm{O})-\mathrm{O}-$ ].

Another group of fractions eluted from the first column of the extract with hexane/EtOAc 2:8 (Group 19) was subjected to a further silica gel column using a hexane, ethyl acetate and methanol gradient, from which a white solid was isolated $(9.0 \mathrm{mg})$ and identified as dehydroaustin (3) (m.p. 281-284 ${ }^{\circ} \mathrm{C}$ ) by uni and bidimensional NMR. ${ }^{14}$

Still from the initial column of the crude extract, group 33 (633.9 $\mathrm{mg}$ ), eluted from EtOAc/MeOH 7:3, was rechromatographed using a hexane, ethyl acetate and methanol gradient to furnish, in the fractions eluted from hexane/ethyl acetate $1: 1$, a white solid $(\mathbf{4}, 12.5$ $\mathrm{mg}$ ), identified as penicillic acid, m.p. $81-84^{\circ} \mathrm{C}(\mathbf{4}) .^{2}$

\section{Antimicrobial activity assays by disc difusion ${ }^{16}$}

The amount of $2.0 \mathrm{mg}$ of each substance was solubilized in 1.0 $\mathrm{mL}$ of chloroform and $50.0 \mu \mathrm{L}$ of each solution were quantitatively loaded on a disc paper to make a final concentration of $100.0 \mu \mathrm{g} / \mathrm{disc}$. The solvent was removed by dry air. The test plates were prepared with $7.5 \mathrm{~mL}$ of Number 1 Antibiotic Medium and sterilized in autoclave for $15 \mathrm{~min}$ at $121{ }^{\circ} \mathrm{C}$. An aliquot of $0.4 \mathrm{~mL}$ of the diluted bacteria inoculum $(500.0 \mu \mathrm{L}$ of stock culture in $2.0 \mathrm{~mL}$ of BHI left for $18 \mathrm{~h}$ at $37^{\circ} \mathrm{C}$ ) was transferred to $4.5 \mathrm{~mL}$ of saline solution) and homogenized using a vortex. A negative control was set using a disc impregnated with $50.0 \mu \mathrm{L}$ of chloroform, and chloramphenicol $(30.0 \mu \mathrm{g} / \mathrm{disc})$ was used as positive control of antibacterial test. Experiments were run in duplicate. The result was ridden after incubation for $24 \mathrm{~h}$ at $37^{\circ} \mathrm{C}$.

\section{Minimum inhibitory concentration by broth dilution test $^{17}$}

Minimum inhibitory concentration (MIC) was evaluated by the broth dilution test using standard inoculums of $10^{-5} \mathrm{CFU} \mathrm{mL}^{-1}$. Serial
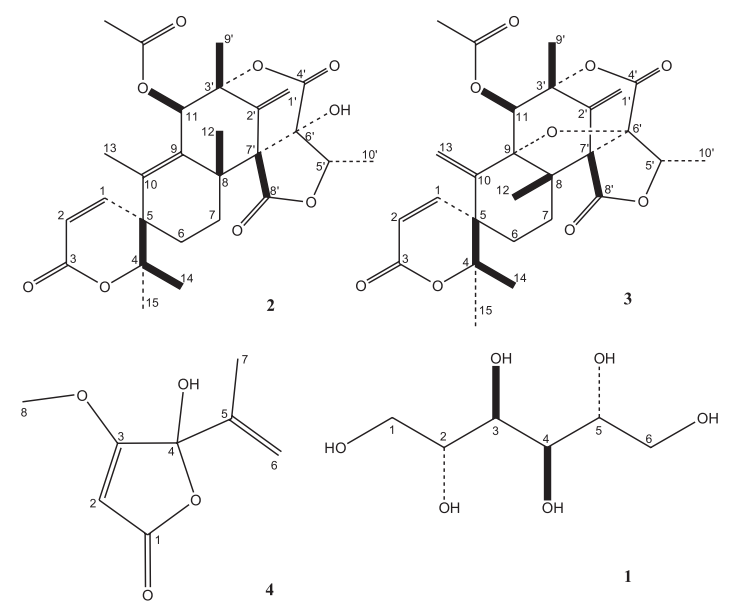

Figure 1. Strucutres of manitol (1), austin (2), dehydroaustin (3) and penicillic acid (4) isolated from P. brasilianum

dilutions of test compounds and extracts, previously dissolved in dimethylformamide (DMF, $2.0 \mathrm{mg} / \mathrm{mL}$ ), were prepared to final concentrations of $512,256,128,64,32,16,8,4,2$, and $1 \mu \mathrm{g}$ in $1 \mathrm{~mL}$ of BHI (Brain Hearth Infusion) medium. To each tube, $100 \mu \mathrm{L}$ of the inoculum were added. MIC, defined as the lowest concentration of the test compound which inhibits the visible growth after $18 \mathrm{~h}$, was determined visually after incubation for $18 \mathrm{~h}$ at $37{ }^{\circ} \mathrm{C}$. Tests using DMF as negative control and chloramphenicol (bacteria) or miconazole (fungus) as positive control were carried out in parallel. All tests were performed in duplicate with full agreement between both results.

\section{Acetylcholinesterase inhibition on thin layer chromatography ${ }^{18}$}

Crude ethylacetate extract and isolated compound austin (2), dihydroaustin (3) and penicillic acid (4) were spotted on a TLC plate. A positive control (Huperzine-A) was also spotted. After elution, the plate was sprayed with acetylcholinesterase solution and incubated at $37^{\circ} \mathrm{C}$. After $20 \mathrm{~min}$, a solution containing $\alpha$-naphthyl acetate solution and Fast Blue B salt was sprayed onto the plate. Active compounds showed a purple spot just after spraying and it turned white after a few hours (Figure 1S, supplementary material).

\section{RESULTS AND DISCUSSION}

Compound 1 that has spontaneously precipitated in some polar fractions was tentatively identified as D-mannitol. Its ${ }^{1} \mathrm{H}$ NMR spectrum showed signals in the region of $\delta 3.60-3.83$ and only three signals were observed in the ${ }^{13} \mathrm{C}$ NMR spectrum. Sub-spectrum DEPT revealed one of them to be a methylene group. A broad band, typical of hydroxylated compounds was observed in the IR spectrum at 3300 $\mathrm{cm}^{-1}$. These spectroscopic data were consistent with the presence of the symmetrical polyalcohol D-mannitol, considered the most abundant of all the soluble polyalcohols found in fungi. ${ }^{19}$ It has been reported that D-mannitol inhibits the angiotensin conversion enzyme (ECA) having also anti-hypertensive activity. ${ }^{20}$ Acyclic polyalcohols like mannitol are usually produced by fungi belonging to the phylos Ascomycota and Basidiomycota. ${ }^{21}$ Their biological function is still unknown but some authors suggest that these compounds act as energy and carbon source, having also a protecting activity, as for trealose, a compound that is responsible for spores germination when the fungi are under stressing conditions. ${ }^{19,21}$ Polyalcohols profile has been pointed out as a quimiotaxonomic marker for fungi. ${ }^{19}$

The second compound to be isolated was a white solid that presented, in the IR spectrum, one band of hydroxyl group and 
three bands of carbonyl groups. ${ }^{1} \mathrm{H}$ NMR spectrum was typical of terpenoids with a concentration of signals between $\delta_{\mathrm{H}} 1.1$ and 2.0. A careful analysis of uni- and bidimensional spectra of this compound allowed to construct parts of the molecule, including an $\alpha, \beta$ unsaturated $\delta$-lactone fragment, which led, together with the other spectroscopic data, to its identification as austin (2). ${ }^{12}$

Due to their high structural complexity, NMR data for meroterpenoids are somehow confusing in the literature. In this way, there is a disagreement between data reported for austin by Hayashi et al. ${ }^{11}$ concerning to the chemical shifts of C14 and C15. In our study, there were found spatial correlations in NOESY correlations map among H1 x H2, H1 x H7 $\alpha$, H5' x H10', OH x H10' and H13 x H15 (Figure 2). Based on these correlations, $\beta$ configuration was adopted for methyl group at $\delta_{\mathrm{C}} 25.7$, while Hayashi et al. attributed $\alpha$ configuration for the same carbon.

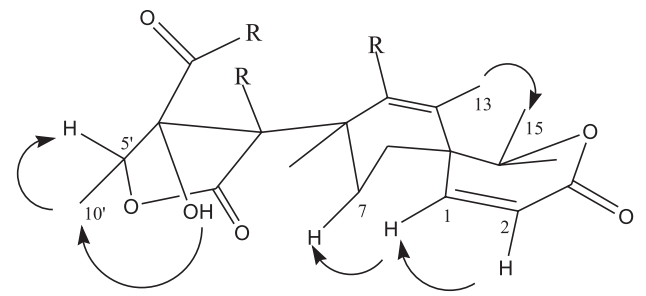

Figure 2. Partial structure of austin showing some correlations found in the NOESY correlations map

The third compound isolated showed several NMR spectra similarities with austin spectra. The methyl group signal at $\delta_{\mathrm{H}} 1.65$ showed to be coupled to the hydrogen at $\delta_{\mathrm{H}} 5.29(\mathrm{~J} 6.8 \mathrm{~Hz})$. Full NMR data indicated this compound to be dehydroaustin (3), which presents a second exocyclic double bound and formation of an oxygen bridge from C6 hydroxyl group and C9, in relation to austin (Figure 1). Dehydroaustin was first reported as a metabolite of Aspergillus sp. ${ }^{22}$, but it has also been reported from Penicillium species. ${ }^{12,14}$ This is, in the best of our knowledge, the first time that the meroterpenes austin and dehydroaustin have been isolated from this species. Compound $\mathbf{4}$ was isolated as a white solid and identified by ${ }^{1} \mathrm{H}$ and ${ }^{13} \mathrm{C}$ NMR as well as by comparison with the original sample as penicillic acid ${ }^{22}$ (Figure 1).

In the antibacterial assay by disc difusion, the crude extract (100 $\mu \mathrm{g} / \mathrm{mL})$ was active against all tested bacteria but neither austin (100 $\mu \mathrm{g} / \mathrm{mL})$ nor dehydroaustin $(100 \mu \mathrm{g} / \mathrm{mL})$ presented activity towards any of the tested bacteria. Penicillic acid $(100 \mu \mathrm{g} / \mathrm{mL})$ was active against S. aureus $(\mathrm{IZ}=18 \mathrm{~mm})$, L. monocytogenes $(\mathrm{IZ}=26 \mathrm{~mm})$, B. cereus $(\mathrm{IZ}=15 \mathrm{~mm})$, S. typhimurium $(\mathrm{IZ}=15 \mathrm{~mm})$, E. coli $(\mathrm{IZ}=15 \mathrm{~mm})$ and C. freundii $(\mathrm{IZ}=16 \mathrm{~mm})$; for $E$. coli, penicillic acid was more active than the control, chloramphenicol, which presented $\mathrm{IZ}=13 \mathrm{~mm}$. MIC values were determined penicillic acid that showed MIC value of 512 $\mu \mathrm{g} / \mathrm{mL}$ against $S$. aureus and $S$. typhimurium and $256 \mu \mathrm{g} / \mathrm{mL}$ against L. monocytogenes, B. cereus, $S$. typhimurium, E. coli and C. freundii.

Crude extract, austin (2), dihydroaustin (3) and penicillic acid (4) were also tested for acetylcholinesterase inhibition by TLC assay (Figure 1S, supplementary material). ${ }^{18}$ Penicillic acid was again the only active compound, showing a clear inhibition zone. When analyzing the activity of a series of closely related compounds for acethylcholinesterase inhibition, Toda et al. ${ }^{23}$ reported that structurally flexible compounds would be more active than rigid ones due to the steric hindrance caused by the later in acetylcholinesterase active site. These findings were corroborated by kovarik et al. ${ }^{24}$ and may be correlated to the inactivity of austin and dehydroaustin. Penicillic acid, a flexible small molecule was, therefore, more likely expected to achieve a suitable conformation to fit the enzyme.

\section{SUPPLEMENTARY MATERIAL}

TLC profile of the tested material in acetylcholinesterase assay can be found in the supplementary material (Figure 1S), as a pdf file, at http://quimicanova.sbq.org.br, free of charge.

\section{ACKNOWLEDGMENTS}

The authors thank International Foundation for Science (IFS, grant F/3564-2), Fundação de Amparo à Pesquisa do Estado de Minas Gerais (FAPEMIG) for financial support and Conselho Nacional de Desenvolvimento Científico e Tecnológico (CNPq) for a grant to J. A. Takahashi and Universidade Federal de Ouro Preto for a scholarship for B. T. M. Schürmann. We thank G. S. Ataliba and E. L. de Souza for technical assistance and A. A. P. Bracarense for preparing the extract.

\section{REFERENCES}

1. Tuthill, D. E.; Frisvad, J. C.; Christensen, M.; Mycologia 2001, 93, 298.

2. Kang, S. W.; Kim, S. W.; Biotechnol. Lett. 2004, 26, 695.

3. Frisvad, J. C.; Smedsgaard, J.; Larsen, T. O.; Samson, R. A.; Studies in Mycology 2004, 49, 201.

4. Afiyatullov, S. S.; Kalinovskii, A. I.; Pivkin, M. V.; Dmitrenok, P. S.; Kuznetsova, T. A.; Chem. Nat. Compd. 2004, 40, 615.

5. Fujita, T.; Makishima, D.; Akiyama, K.; Hayashi, H.; Biosci. Biotechnol. Biochem. 2002, 66, 1697.

6. Fujita, T.; Hayashi, H.; Biosci. Biotechnol. Biochem. 2004, 68, 820.

7. Fill, T. P.; Santos, R. M. G.; Barrisson, A.; Rodrigues-Filho, E.; Souza, A. Q. L.; Z. Naturforsch. C 2009, 64, 355.

8. Takahashi, J. A.; Castro, M. C. M.; Souza, G. G.; Lucas, E. M. F.; Bracarense, A. A. P.; Abreu, L. M.; Marriel, I. E.; Oliveira, M. S.; Floreano, M. B.; Oliveira, T. S.; J. Mycologie Med. 2008, 18, 198.

9. Cueto, M.; Macmillan, J. B.; Jensen, P. R.; Fenical, W.; Phytochemistry 2006, 67, 1826

10. Chexal, K. K.; Springer, J. P.; Clardy, J.; Cole, R. J.; Kirksey, J. W.; Dorner, J. W.; Cutler, H. G.; Strawter, B. J.; J. Am. Chem. Soc. 1976, 98 , 6748.

11. Hayashi, H.; Mukaihara, M.; Murao, S.; Arai, M.; Lee, A. Y.; Clardy, J.; Biosci., Biotechnol. Biochem. 1994, 58, 334.

12. Santos, R. M. G.; Rodrigues-Filho, E.; Phytochemistry 2002, 61, 907.

13. Santos, R. M. G.; Rodrigues-Filho, E.; J. Braz. Chem. Soc. 2003, 14, 722.

14. Santos, R. M. G.; Rodrigues-Filho, E.; Z. Naturforsch. 2003, 58, 663.

15. Hagiwara, S.; Takahashi, M.; Shen, Y.; Kaihou, S.; Tomiyama, T.; Yazawa, M.; Tamai, Y.; Sin, Y.; Kazusaka, A.; Terazawa, M.; Biosci. Biotechnol. Biochem. 2005, 69, 1603.

16. Bauer, S. W.; Kirby, W. M.; Sherris, J. C.; Thurck, M.; Am. J. Pathol. 1966, 45, 493.

17. Takahashi, J. A.; Pereira, C. R.; Pimenta, L. P. S.; Boaventura, M. A. D.; Silva, L. G. F.; Nat. Prod. Lett. 2006, 20, 21.

18. Di Giovanni, S. D.; Borloz, A.; Urbain, A.; Marston, A.; Hostettmann, K.; Carrupt, P. A.; Reist, M.; Eur. J. Pharm. Sci. 2008, 33, 109.

19. Solomon, P. S.; Waters, O. D. C.; Oliver, R. P.; Trends Microbiol. 2007, $15,257$.

20. Feofilova, E. P.; Appl. Biochem. Microbiol. 2001, 37, 124

21. Ramstedt, M.; Jirjis, R.; Soederhaell, K.; New Phytologist 1980, 105 , 281.

22. Simpson, T. J.; Stenzel, D. J.; Bartlett, A. J.; O’Brien, E.; Holker, J. S. E.; J. Chem. Soc., Perkin Trans. 1 1982, 11, 2687.

23. Toda, N.; Iwata, Y.; Tago, K.; Kogen, H.; Kaneko, T.; Miyamoto, S.; Chem-Bio Informatics J. 2003, 3, 46.

24. Kovarik, Z.; Calic, M.; Sinko, G.; Bosak, A.; Arhiv Za Higijenu Rada i Toksikologiju 2007, 58, 201. 


\section{AUSTIN, DEHYDROAUSTIN AND OTHER METABOLITES FROM Penicillium brasilianum}

Betânia T. M. Schürmann

Escola de Farmácia, Universidade Federal de Ouro Preto, Rua Costa Sena, 171, 35400-000 Ouro Preto - MG, Brasil William S. T. Sallum e Jacqueline A. Takahashi*

Departamento de Química, Universidade Federal de Minas Gerais, Av. Antonio Carlos, 6627, 31270-901 Belo Horizonte - MG, Brasil

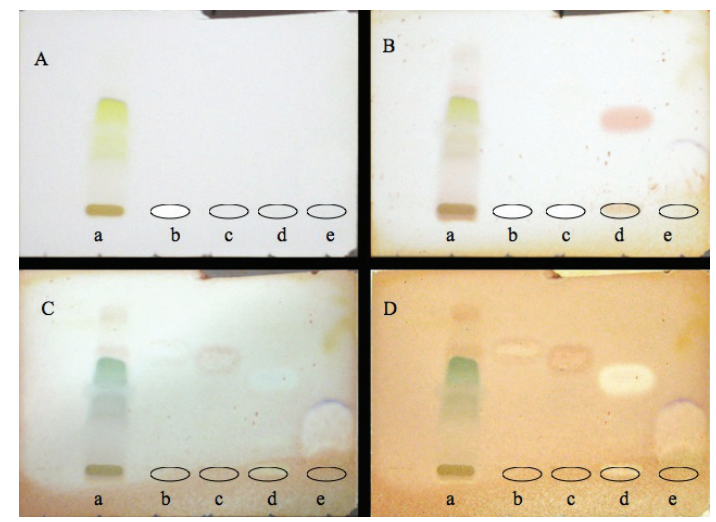

Figure 1S. TLC profiles. A: Before reagents spraying B: Just after reagents spraying C: After 2 hours D: After 6.5 h; white spots refer to positive result. a: P.brasilianum crude extract; $b$ : Austin; : dehydroaustin; $d$ : Penicillic acid; $e$ : Positive control 